\title{
The impact of high crop prices on the use of agro-chemical inputs in France: a structural econometric analysis
}

\author{
Basak Bayramoglu* Raja Chakir ${ }^{\ddagger}$
}

March 30, 2016

\begin{abstract}
World crop prices increased dramatically during the period 2006-2009. In this context of high crop prices, farmers may tend to increase the amount of agro-chemical inputs they use in order to increase yield and manage risks related to crop production. These practices could, however, have potentially adverse environmental effects in terms of loss of biodiversity and increased water and air pollution. This study uses a structural econometric model to measure the effects of crop prices on demand for agro-chemical inputs and land allocation. We study individual farms observed in the period 2006 to 2009 in the French Département de la Meuse. We estimate a multi-output profit function using farm-level panel data. Our results show that an increase in the rapeseed price, which is the principal feedstock for the production of biodiesel in France, has a positive and significant effect on demand for agrochemical inputs. Higher rapeseed prices also induce an expansion in the land area allocated to rapeseed at the expense of barley and set-aside. These results suggest that changes in the rapeseed price, partly driven by biofuel policies, induce changes in demand for chemicals and land allocation which may have potentially adverse effects on the environment.
\end{abstract}

*Economie Publique, INRA, AgroParisTech, Université Paris-Saclay, 78850 Thiverval-Grignon, France. email: basak.bayramoglu@grignon.inra.fr

${ }^{\dagger}$ Economie Publique, INRA, AgroParisTech, Université Paris-Saclay, 78850 Thiverval-Grignon, France. email: raja.chakir@grignon.inra.fr

${ }^{\ddagger}$ We thank the Editor of the journal for his help and his overall contribution to the paper, and two anonymous referees for their very detailed and helpful comments. We thank the Centre de Gestion et d'Economie Rurale de la Meuse/CER for providing the data and Jean-Pierre Butault, Nathalie Delame and Guy Millet for their helpful comments and suggestions. This research was supported by the European Union's Seventh Framework Programme FP7/2007-2011 under Grant Agreement n 290693 FOODSECURE (see GA Article II.30). The authors only are responsible for any omissions or deficiencies. Neither the FOODSECURE project and any of its partner organizations, nor any organization of the European Union or European Commission are accountable for the content of this paper. 
Keywords: Pesticide demand, fertilizer demand, agro-chemical inputs, land allocation, rapeseed price, fertilizer tax, biofuel policies, panel data model. JEL codes: Q12, C33. 


\section{Introduction}

World crop prices increased dramatically in 2007. For example, in France during the period 2006-2010, the rapeseed price increased by $60 \%$, going from $€ 261$ up to $€ 416$ per ton. This period of high crop prices was not limited to France; it was observed in all world cereal markets. Three principal factors have been identified as the drivers of this worldwide increase in food prices: rising demand from emerging markets for key commodities, dollar depreciation, and biofuel policies (Abbott et al. 2009). The first two factors are cyclical variations; the last relates to policies encouraging production and use of biofuels. According to Baier et al. (2009), for the period 2006-2008, the increase in world biofuel production induced increases in corn, soybean, and rapeseed prices by $27 \%, 21 \%$ and $18 \%$ respectively.

High crop prices can encourage farmers to change their agricultural practices, which in turn may induce potential adverse effects for the environment. For instance, it has been shown that higher crop prices due to the biofuel production lead to nitrogen runoff and water pollution problems (Secchi et al., 2011; Langpap and Wu, 2011), induce losses in biodiversity (Secchi et al. 2007), and exacerbate the climate change problem due to greenhouse gas (GHG) emissions from land-use changes (Searchinger et al., 2008). The objective of this study is to measure how increased crop prices affect demand for agro-chemical inputs among French farmers. More specifically we test the hypothesis that an increase in crop prices increases demand for chemical inputs (fertilizers and pesticides). We estimate a multi-output profit function based on a panel of individual farms in France observed from 2006 to 2009. Using the estimated value of the demand elasticity of pesticides and fertilizers with respect to the rapeseed price, rapeseed being the principal feedstock for biodiesel production in France, we simulate the effects of European Union (hereafter denoted as EU) biofuel policy on the use of agro-chemical inputs. These estimates provide a basis for discussion of a policy instrument, namely a fertilizer tax, in France to limit the use of fertilizers which may affect surface water and groundwater quality.

France is particularly appropriate for analysing demand for agro-chemicals because water pollution by nitrates and pesticides, mainly due to agricultural and livestock production, is a major issue there. France is the world's third largest user of pesticides and the seventh largest consumer of fertilizers. In September 2014 the European Court of Justice ruled that France had failed to fulfill its obligation to comply with the EU Water Framework Directive. After its previous judgments of March 2001 (too many nitrates in Brittany catchments) and June 2013 (incomplete designation of "vulnerable" areas of water pollution by nitrates), the decision of September 2014 was thus the third time the European Court had ruled against France. On this occasion it was censured for the insufficient measures taken. 
The EU Water Framework Directive specifies the objective of good or very good surface water quality by 2015 for all member states. In France in 2013, only $48.2 \%$ of surface water resources are in a good situation regarding the chemical status. The situation is better for groundwater resources as $67 \%$ of them are in a good situation in 2013. The main causes of the bad status of the remaining $32.8 \%$ of groundwater resources are nitrate pollution (17\% of water resources) and pesticide pollution (15.8\% of water resources) (Katell and Michon, 2015).

The French Ministry of Agriculture recently implemented the Ecophyto Plan aimed at reducing agricultural pesticide use by $50 \%$ by 2018 . Environmental taxes on sales of pesticides ("redevances pour pollutions diffuses") have been introduced in order to achieve this objective. The tax rate varies depending on the type of phytosanitary product: it is $€ 2$ per kg for environmentallyharmful organic substances, $€ 0.90$ per $\mathrm{kg}$ for mineral substances, and $€ 5.10$ per $\mathrm{kg}$ for toxic substances. Despite the extent of nitrogen pollution, there is no tax on fertilizers in France.

The paper is organized as follows. Section 2 provides a brief overview of the literature on the estimation of multi-output models and the literature on the environmental impacts of biofuel production. Section 3 presents the empirical model and the estimation method. Section 4 discusses the data, and the estimation results. We provide a simulation exercise to assess the impact of alternative crop price scenarios, found in the literature, on the use of agro-chemical inputs, and discuss a policy instrument to limit their use. Section 5 concludes by discussing how our estimates could contribute to the ongoing debate on the potential adverse effects of biofuel development on the environment.

\section{Literature}

Our paper is related to two strands in the literature. The first strand deals with the estimation of multi-output models to measure how crop prices affect farmers' production decisions. Multioutput models are able to take into account cross-price elasticities between different products (see, among others, Moro and Sckokai (1999); Williams and Shumway (2000); Arnade and Kelch (2007); Fezzi and Bateman (2011); Lacroix and Thomas (2011); Laukkanen and Nauges (2014)). Arnade and Kelch (2007) propose a method to estimate individual crop areas and output responses to a change in prices, by including in the estimations shadow price equations for each crop area allocation. The estimation method is applied to aggregate data for the state of Iowa during the period 1960-1999. Lacroix and Thomas (2011) estimate a multi-output model for a panel of French farmers during 1995-2001. They incorporate a crop-selection mechanism which allows them to control for the influence of crop rotation on land use and output decisions. The study most closely related to ours is Laukkanen and Nauges (2014) which estimates a multi-output 
profit function in order to assess the effects of agri-environmental payments on agro-chemical inputs and land-use decisions. The estimations are based on a sample of individual Finnish grain farmers over the period 1996-2005. The estimation results show modest reductions in fertilizer use in response to agri-environmental payments, which however increase the area allocated to grain and reduce the area of set-aside land. The authors combine these estimates with environmental production functions in order to assess the damage costs associated with nutrient pollution.

The second strand in the literature focuses on changes in intensive and extensive margins of production following an increase in energy crop prices. The adverse environmental effects due to higher crop prices could come either from changes in the intensive margin of production, through the increased use of agro-chemical inputs, or from changes in the extensive margin of production through land-use changes. In relation to cropping intensification, Louhichi and Valin (2012) estimate that for France higher rapeseed prices driven by EU biofuel policies will increase by 2020 pesticide use by $5 \%$ and $\mathrm{N}_{2} \mathrm{O}$ emissions by $2.5 \%$. Lankoski and Ollikainen (2011) show in the case of Finland that biodiesel based on rapeseed and ethanol produced from wheat and barley lead to nitrogen and phosphorus runoff. For the extensive margin, Hausman (2012) estimates the impact of sugarcane and soybean prices on acreage conversion in Brazil. High corn prices in the United States (hereafter denoted as US) are estimated to induce nitrate runoff, nitrate percolation, and soil water erosion (Langpap and Wu (2011)), and to have adverse effects on water quality (Secchi et al. (2011)). Langpap and Wu (2011) estimate the environmental impacts of higher commodity prices driven by ethanol mandates in the US, by combining economic and physical models. The economic models provide information on the changes in crop mix and land use allocation (cropland vs. noncropland). These estimated changes are then used to evaluate local environmental impacts such as nitrate runoff, nitrate percolation, and soil water erosion. Following a $\$ 3$ increase in the corn price in the Corn Belt and Lake States, fertilizer use is estimated to increase by $18 \%$ and $18.7 \%$, and pesticide use by $23.1 \%$ and $27.5 \%$ respectively. With regard to the climate change problem, Timilsina and Mevel (2013) forecast the impacts of worldwide biofuel mandate policies on the extent of GHG emissions triggered by land-use changes.

To the best of our knowledge, there has been no econometric assessment of the effects of crop prices on cropping intensification and land allocation decisions for the case of France in the recent context of high agricultural commodity prices, partly driven by biofuel policies. Our study aims to fill this gap and to shed some light on this question. The structural econometric approach presented below, allows us systematically to estimate the effects of crop prices on both 
cropping intensification and land allocation decisions.

\section{The empirical model}

We consider a risk-neutral farmer who uses $K$ variable inputs and one fixed but allocatable factor (land) to produce $C$ different crops, where : $c$ is the crop index, $c=1, \ldots, C ; p_{c}$ is the price of $\operatorname{crop} c$; $y_{c}$ is the output level of crop $c ; x$ is a $K$ vector of variable inputs; $w_{k}$ is the price of input $k ; l_{c}$ is the land allocated to crop $c$ and $L$ is the total available land $\left(\sum_{c=1}^{C} l_{c}=L\right)$.

Following Chambers and Just (1989), the multi-crop profit function for a joint input technology given the fixed factor allocation (land) can be written as:

$$
\Pi(p, w, \tau, L)=\max _{y, x, l}\left\{\sum_{c=1}^{C} p_{c} y_{c}-\sum_{k=1}^{K} w_{k} x_{k}+0.25 * \sum_{c=1}^{C} \tau_{c} l_{c}+S F P ; \sum_{c=1}^{C} l_{c}=L\right\}
$$

where $\tau_{c}$ is the subsidy rate per hectare for crop $c$. The $S F P$ or single farm payment is calculated on a historical basis independent of actual production, and was introduced by the 2003 reform of the Common Agricultural Policy (CAP). Decoupling refers to the removal of the link between receipt of a direct payment and production of a specific product. Prior to the reform, farmers received a direct payment only if they produced the specific product with which the direct payment was associated. The 2003 CAP reform permitted member states to continue to couple a small number of direct payments to production (in the case of France, 25\% of production) 1

Following Lacroix and Thomas (2011) and Laukkanen and Nauges (2014), the normalized quadratic profit function is written as:

$$
\begin{aligned}
\bar{\Pi}=\alpha_{0} & +\sum_{c=1}^{C} \alpha_{c} \bar{p}_{c}+\sum_{k=1}^{K-1} \beta_{k} \bar{w}_{k}+\sum_{c=1}^{C} \gamma_{c} \bar{\tau}_{c}+\frac{1}{2} \sum_{c=1}^{C} \sum_{c^{\prime}=1}^{C} \alpha_{c c^{\prime}} \bar{p}_{c} \bar{p}_{c^{\prime}}+\frac{1}{2} \sum_{k=1}^{K-1} \sum_{k^{\prime}=1}^{K-1} \beta_{k k^{\prime}} \bar{w}_{k} \bar{w}_{k^{\prime}}+\frac{1}{2} \sum_{c=1}^{C-1} \sum_{c^{\prime}=1}^{C} \gamma_{c c^{\prime}} \bar{\tau}_{c} \bar{\tau}_{c^{\prime}} \\
& +\sum_{k=1}^{K-1} \sum_{c=1}^{C} \delta_{c k}^{p w} \bar{p}_{c} \bar{w}_{k}+\sum_{c^{\prime}=1}^{C} \sum_{c=1}^{C} \delta_{c c^{\prime}}^{p \tau} \bar{p}_{c} \bar{\tau}_{c^{\prime}}+\sum_{k=1}^{K-1} \sum_{c=1}^{C} \delta_{c k}^{w \tau} \bar{\tau}_{c} \bar{w}_{k}+\sum_{c=1}^{C} \lambda_{c}^{p L} \bar{p}_{c} L+\sum_{c=1}^{C} \lambda_{c}^{\tau L} \bar{\tau}_{c} L+\sum_{k=1}^{K-1} \lambda_{k}^{w L} \bar{w}_{k} L,
\end{aligned}
$$

where $\bar{\Pi}=\frac{\Pi}{w_{K}}, \bar{p}_{c}=\frac{p_{c}}{w_{K}}, \bar{w}_{k}=\frac{w_{k}}{w_{K}}, \bar{\tau}_{c}=\frac{\tau_{c}}{w_{K}}$ indicate respectively normalized profit, output price, input price, and subsidy rate, and $w_{K}$ is the price of the numeraire.

Differentiating the profit in (2) with respect to output prices $\bar{p}_{c}$ yields the output level of crop $c$ (Hotelling Lemma):

\footnotetext{
${ }^{1}$ For more details on 2003 CAP reform, see Butault (2004), chapter 3.
} 


$$
y_{c}=\frac{\partial \Pi}{\partial \bar{p}_{c}}=\alpha_{c}+\sum_{c^{\prime}=1}^{C} \alpha_{c c^{\prime}} \bar{p}_{c^{\prime}}+\sum_{k=1}^{K-1} \delta_{c k}^{p w} \bar{w}_{k}+\sum_{c^{\prime}=1}^{C} \delta_{c c^{\prime}}^{p \tau} \tau_{c^{\prime}}+\lambda_{c}^{p L} L, \forall c=1, \ldots, C,
$$

Differentiating the profit in (2) with respect to input prices $\bar{w}_{k}$ yields the variable input demand equation (Hotelling Lemma):

$$
-x_{k}=\frac{\partial \Pi}{\partial \bar{w}_{k}}=\beta_{k}+\sum_{k^{\prime}=1}^{K-1} \beta_{k k^{\prime}} \bar{w}_{k^{\prime}}+\sum_{c=1}^{C} \delta_{c k}^{p w} \bar{p}_{c}+\sum_{c=1}^{C} \delta_{c k}^{w \tau} \bar{\tau}_{c}+\lambda_{k}^{w L} L, \forall k=1, \ldots, K-1,
$$

We follow the paper of Lacroix and Thomas (2011) and derive optimal land allocations by computing the derivatives of the profit function in 22 with respect to the crop area subsidies ${ }^{2}$ $\bar{\tau}_{c}$ :

$$
0.25 * l_{c}=\frac{\partial \Pi}{\partial \bar{\tau}_{c}}=\gamma_{c}+\sum_{c^{\prime}=1}^{C} \gamma_{c c^{\prime}} \bar{\tau}_{c^{\prime}}+\sum_{k=1}^{K-1} \delta_{c k}^{w \tau} \bar{w}_{k}+\sum_{c^{\prime}=1}^{C} \delta_{c c^{\prime}}^{p \tau} \bar{p}_{c}+\lambda_{c}^{L \tau} L, \forall c=1, \ldots, C,
$$

The profit function properties imply that the profit function is (1) non-decreasing in output prices $p$, non-increasing in input prices $w,(2)$ homogeneous of degree 1 in prices $(p, w, \tau),(3)$ convex in prices $(p, w),(4)$ continuous in prices $(p, w)$. These properties imply that some conditions need to be imposed on the parameters, such as symmetry. With the normalized form of the profit, the condition of linear homogeneity is automatically satisfied.

We need also to impose the land adding-up condition $\sum_{c=1}^{C} l_{c}=L$, which in our case imposes the following conditions on the parameters:

$$
\begin{aligned}
& \sum_{c^{\prime}=1}^{C} \gamma_{c c^{\prime}}=\sum_{c^{\prime}=1}^{C} \delta_{c k}^{w \tau}=\sum_{c^{\prime}=1}^{C} \delta_{c c^{\prime}}^{p \tau}=\sum_{c^{\prime}=1}^{C} \gamma_{c}=0 ; \forall k, \forall c \\
& \sum_{c^{\prime}=1}^{C} \lambda_{c}^{L \tau}=0.25
\end{aligned}
$$

We calculate the elasticities of inputs, output, and land allocation with respect to prices and subsidies. They are computed by multiplying the corresponding parameter (coefficient of price or subsidy rate in the land, output or input equation) by the ratio of the normalized price (or

\footnotetext{
${ }^{2}$ This approach has some limitations which are important to be acknowledged. The first is that land equations for crops which do not receive arable area payments are not identified. The second is that this creates a separation between the crop production function and the land production function, which means that the only rationale for allocating land to a certain crop is the associated arable area payment, and not the fact that a crop can be sold for a certain price and produce revenues. The third limitation is that in the land use, output and input equations the impact of prices is assumed to not depend on the size of the farm and, therefore, one can obtain misleading results if farm size differ significantly within the sample.
} 
subsidy rate) and land area, output level or input level. For example, the elasticity of input demand with respect to its own price, output price, and subsidy rates, can be calculated as follows:

$$
\begin{gathered}
\varepsilon_{x_{k} \bar{w}_{k^{\prime}}}=\frac{\partial x_{k}}{\partial \bar{w}_{k^{\prime}}} \times \frac{\bar{w}_{k^{\prime}}}{x_{k}}=-\beta_{k k^{\prime}} \times \frac{\bar{w}_{k^{\prime}}}{x_{k}} \\
\varepsilon_{x_{k} \bar{p}_{c}}=\frac{\partial x_{k}}{\partial \bar{p}_{c}} \times \frac{\bar{p}_{c}}{x_{k}}=-\delta_{c k}^{p w} \times \frac{\bar{p}_{c}}{x_{k}} \\
\varepsilon_{x_{k} \bar{\tau}_{c}}=\frac{\partial x_{k}}{\partial \bar{\tau}_{c}} \times \frac{\bar{\tau}_{c}}{x_{k}}=-\delta_{c k}^{w \tau} \times \frac{\bar{\tau}_{c}}{x_{k}}
\end{gathered}
$$

We estimate simultaneously the system of equations (3.44 5) after imposing symmetry restrictions and land adding-up conditions. The explanatory variables are output prices, input prices, the vector of subsidy rates and total land. All prices and subsidies are normalized by the price of seed. Since we observe panel data, we control in our model for unobserved individual heterogeneity. From an econometric standpoint, individual effects can be assumed to be either random or fixed. The choice between the random-effect (RE) or fixed-effect (FE) specification depends on the model and data (Baltagi, 1995). According to Greene (2008) (chapter 11, page 347): "... the crucial distinction between fixed and random effects is whether the unobserved individual effect embodies elements that are correlated with the regressors in the model, not whether these effects are stochastic or not". A RE model requires that the individual effects are independent of regressors. We choose to model individual effects through FE specification ${ }^{3}$, as this choice allows the individual effects to be correlated with exogenous regressors. To estimate the FE model, we apply the within transformation to all variables and estimate a Seemingly Unrelated Regression Equations (SURE) model. The within transformation, which causes the variables to deviate from their individual means, cancels out time-invariant unobserved individual effects.

\footnotetext{
${ }^{3}$ As suggested by a reviewer, this fixed effect estimator is consistent only if these effects are additive. Adding interaction effects is a very good idea, but because our model is structural their addition would involve changing the whole set of constraints.
} 


\section{Data description and estimation results}

\subsection{Data description}

The study is conducted on a sample of French farmers from the Département de la Meuse $4^{4}$ Our data are provided by the Meuse Management Centre (Centre de Gestion de la Meuse), and they were used in previous studies (Boussemart et al., 2011; Chakir and Hardelin, 2014). Agricultural land in Meuse represents 54\% of the department's overall area: 36\% is arable land and the remaining $18 \%$ is grassland. Cereals and oil crops are the main agricultural products and account for $81 \%$ of the arable area. Our sample is an unbalanced panel observed between 2006 and 2009. An interesting feature of our database is that it contains detailed information on the main inputs for each crop: fertilizers (nitrogen, phosphorous, potassium - NPK) and pesticides (herbicides, fungicides, insecticides, growth regulators). The sampled farms mainly produce cereal and oil crops. The most frequent crop rotation observed in our sample involves wheat, barley, and rapeseed. More than $97 \%, 92 \%$ and $81 \%$ of farmers in our sample produce wheat, barley and rapeseed respectively every year. The percentage of farmers having set aside land varies between $86 \%$ in 2006 and $59 \%$ in 20095

This data set is representative from two standpoints. First, Delame $(2014)$ notes that the acreage of this sample is very representative for all years of the acreage of the Département de la Meuse described by Annual Agricultural Statistics ${ }^{6}$ Permanent pastures occupy less than one third of the total area. Wheat is the most important crop in terms of area (25\%) followed by rapeseed (15\%) and barley. Peas, corn and sunflower are rather marginal crops.

Second, we note that pesticide and fertilizer expenditure per hectare of our sample in 2006, wheat pesticide: $€ /$ ha 132 , barley pesticide: $€ /$ ha 110 , rapeseed pesticide: $€ /$ ha 150 ; wheat fertilizer: $€ /$ ha 141 , barley fertilizer: $€ /$ ha 113 , rapeseed fertilizer: $€ /$ ha 133 (see Table 1), are comparable to those from FADN data..$^{7}$ On average for all crops, we note that the statistics of our sample are comparable to the expenditure of other agricultural regions such as Ile-deFrance (Fertilizer: $€ /$ ha 106; Pesticide: $€ /$ ha 92), Champagne-Ardenne (Fertilizer: $€ /$ ha 147;

${ }^{4}$ The Département de la Meuse is located in a relatively small French territorial division $\left(6,211\right.$ kilometers $\left.^{2}\right)$. It is one of four départements in the Lorraine Région. Information about Département de la Meuse and a map can be found at http://en.wikipedia.org/wiki/Meuse

${ }^{5}$ The presence of censored observations in land areas is important to be acknowledged. Econometrically dealing with multiple censoring with panel data and SURE is a challenge that is beyond the scope of this paper. For examples of studies that addressed this issue, see Fezzi and Bateman (2011), Lacroix and Thomas (2011), and Platoni et al. (2012).

${ }^{\circ}$ Source: http://agreste.agriculture.gouv.fr/enquetes/statistique-agricole-annuelle-saa/

${ }^{7}$ The FADN data is representative at the regional level, covering a larger spatial area than that of départements. The FADN data does not distinguish the levels of inputs used for each crop. 
Pesrticide: $€ /$ ha 133) and Lorraine (Fertilizer: $€ /$ ha 132; Pesticide: $€ /$ ha 151).

We now describe how the data is constructed. Output crop prices are computed using a unit value approach, by dividing annual crop sales by the quantity produced. In doing so, we are aware that crop prices depend on the quantity sold but the calculated prices are annual average prices. Given that crop prices depend on the crop quality (protein content) and that they are subject to seasonal variations as well, the relationship between the average annual price and quantity sold is rather complex. We also constructed unit subsidy rates for each crop area and land setaside by dividing the total subsidy by the associated area. Physical quantities of pesticides and fertilizers need to be observed to augment the system of estimated equations. In our data we observe only expenditure on pesticides, which we divided by a national pesticide price index to calculate pesticide demand. With regard to fertilizers, we observe physical quantities as well as expenditure, enabling us to calculate the individual average price of fertilizers.

The summary statistics presented in Table 1 show that, in our sample, rapeseed prices increased by $19 \%$ between 2006 and 2009. This is fairly large compared to the observed increase at the national level $(7 \%)$. Table 1 shows also that expenditure on fertilizers for rapeseed increased by $88 \%$ whereas rapeseed area increased by about $50 \%$. Fertilizer expenditure is fairly similar in 2006 and 2007, but then increases significantly in 2008 and 2009. This increase in expenditure could be explained by the sharp increase in fertilizer prices internationally in the period 2008-2009.

\subsection{Estimation results}

We estimate the system of equations presented above 3,4,5. We have then nine equations estimated simultaneously: wheat output, rapeseed output, barley output; wheat area, rapeseed area, barley area, set-aside area; pesticide demand and fertilizer demand. We estimate this system by Within-SURE ${ }^{8}$ (using SAS software). Raw estimation results, which are used to calculate elasticities, are not reported here but are available from the authors upon request.

We estimate the elasticity of crop output, input demand, and land allocation decisions with respect to crop and input prices, as well as with respect to subsidy rates as shown in equations $6+7,8$. In our view, the most interesting results are those related to elasticities involving demand for chemical inputs with respect to crop prices and area-subsidy rates. We present these results first.

\footnotetext{
${ }^{8}$ In order to check the robustness of our results we have also estimated the system by OLS. The two methods give very similar results.
} 
Table 1: Descriptive statistics

\begin{tabular}{|c|c|c|c|c|c|c|c|c|}
\hline \multirow[b]{2}{*}{ Variable } & \multicolumn{2}{|c|}{2006} & \multicolumn{2}{|c|}{2007} & \multicolumn{2}{|c|}{2008} & \multicolumn{2}{|c|}{2009} \\
\hline & mean & std & mean & std & mean & std & mean & std \\
\hline Wheat output (t) & 291 & 207 & 297 & 204 & 333 & 216 & 370 & 237 \\
\hline Barley output (t) & 208 & 165 & 183 & 145 & 228 & 181 & 247 & 184 \\
\hline Rapeseed output (t) & 83 & 76 & 100 & 85 & 101 & 84 & 121 & 98 \\
\hline Wheat area (ha) & 42 & 28 & 43 & 28 & 48 & 29 & 48 & 29 \\
\hline Barley area (ha) & 34 & 27 & 35 & 27 & 37 & 29 & 37 & 28 \\
\hline Rapeseed area (ha) & 27 & 24 & 30 & 25 & 30 & 24 & 32 & 26 \\
\hline Set-aside area (ha) & 7 & 9 & 6 & 8 & 3 & 5 & 2 & 4 \\
\hline Wheat price $(€ / \mathrm{t})$ & 111 & 32 & 182 & 36 & 143 & 22 & 107 & 13 \\
\hline Barley price $(€ / \mathrm{t})$ & 85 & 55 & 120 & 91 & 111 & 85 & 69 & 50 \\
\hline Rapeseed price $(€ / \mathrm{t})$ & 186 & 103 & 242 & 116 & 273 & 132 & 222 & 93 \\
\hline Wheat subsidy $(€ /$ ha $)$ & 81 & 11 & 79 & 15 & 75 & 15 & 74 & 13 \\
\hline Barley subsidy (€/ha) & 81 & 12 & 79 & 15 & 75 & 14 & 74 & 12 \\
\hline Rapeseed subsidy (€/ha) & 78 & 43 & 74 & 38 & 74 & 41 & 76 & 37 \\
\hline Set-aside subsidy (€/ha) & 9 & 20 & 8 & 20 & 5 & 19 & 37 & 38 \\
\hline Wheat pesticide $(€ /$ ha) & 132 & 45 & 133 & 44 & 156 & 46 & 163 & 48 \\
\hline Barley pesticide $(€ /$ ha $)$ & 110 & 62 & 111 & 61 & 130 & 71 & 131 & 68 \\
\hline Rapeseed pesticide $(€ /$ ha $)$ & 150 & 88 & 151 & 83 & 167 & 91 & 187 & 91 \\
\hline Set-aside pesticide ( $€ /$ ha) & 6 & 129 & 0 & 3 & 0 & 3 & 0 & 3 \\
\hline Wheat fertilizer $(€ /$ ha $)$ & 141 & 42 & 145 & 40 & 189 & 56 & 237 & 76 \\
\hline Barley fertilizer $(€ /$ ha $)$ & 113 & 61 & 119 & 59 & 152 & 81 & 195 & 109 \\
\hline Rapeseed fertilizer $(€ /$ ha $)$ & 133 & 79 & 139 & 75 & 180 & 102 & 250 & 133 \\
\hline Set-aside fertilizer $(€ /$ ha $)$ & 9 & 199 & 0 & 3 & 0 & 2 & 0 & 0 \\
\hline Observations & $\mathrm{N}=$ & & $\mathrm{N}=5$ & & $\mathrm{~N}=$ & & $\mathrm{N}=$ & \\
\hline
\end{tabular}


Table 2: Elasticities of agro-chemical inputs demand calculated at the sample mean

\begin{tabular}{lcc}
\hline with respect to & Fertilizer demand & Pesticide demand \\
\hline Wheat price & $-0.0701^{* * *}$ & $-0.0541^{* *}$ \\
& $(0.0212)$ & $(0.0252)$ \\
Barley price & $0.1193^{* * *}$ & $-0.1029^{* * *}$ \\
& $(0.0142)$ & $(0.0172)$ \\
Rapeseed price & $0.1789^{* * *}$ & $0.0370^{* * *}$ \\
& $(0.0123)$ & $(0.0143)$ \\
Wheat subsidy & $-0.0023^{* * *}$ & $0.0017^{* *}$ \\
Barley subsidy & $(0.0004)$ & $(0.0008)$ \\
& $0.0015^{* * *}$ & -0.0011 \\
Rapeseed subsidy & 0.0003 & $(0.0008)$ \\
& $(0.0004)$ & 0.0002 \\
Set-aside subsidy & 0.0006 & $(0.0009)$ \\
Fertilizer price & $(0.0005)$ & -0.0011 \\
& $-0.2784^{* * *}$ & $(0.0013)$ \\
Pesticide price & $-0.1028^{* * *}$ & $-0.1097^{* * *}$ \\
\hline$* 0142)$ & $(0.0133)$ \\
& $(0.0125)$ & $(0.0354)$ \\
\hline
\end{tabular}

${ }^{*} \mathrm{p}<0.1 ;{ }^{* *} \mathrm{p}<0.05 ;{ }^{* * *} \mathrm{p}<0.01$

Standard errors in parentheses 
Table 3: Elasticities of output calculated at the sample mean

\begin{tabular}{|c|c|c|c|}
\hline with respect to & Wheat Output & Barley output & Rapeseed output \\
\hline \multirow[t]{2}{*}{ Wheat price } & 0.0148 & $-0.3837 * * *$ & -0.0236 \\
\hline & $(0.0272)$ & $(0.0272)$ & $(0.0223)$ \\
\hline \multirow[t]{2}{*}{ Barley price } & $-0.1965 * * *$ & $0.1812^{* * *}$ & $-0.1178 * * *$ \\
\hline & $(0.0139)$ & $(0.0228)$ & $(0.0144)$ \\
\hline \multirow[t]{2}{*}{ Rapeseed price } & -0.0122 & $-0.1189 * * *$ & $0.1624^{* * *}$ \\
\hline & $(0.0116)$ & $(0.0145)$ & $(0.0190)$ \\
\hline \multirow[t]{2}{*}{ Wheat subsidy } & $0.0016^{* * *}$ & $-0.0057 * * *$ & -0.0004 \\
\hline & $(0.0005)$ & $(0.0005)$ & $(0.0004)$ \\
\hline \multirow[t]{2}{*}{ Barley subsidy } & $-0.0035^{* * *}$ & $0.0080^{* * *}$ & $-0.0039^{* * *}$ \\
\hline & $(0.0004)$ & $(0.0006)$ & $(0.0004)$ \\
\hline \multirow[t]{2}{*}{ Rapeseed subsidy } & $0.0006^{* *}$ & $-0.0016^{* * *}$ & $0.0047^{* * *}$ \\
\hline & $(0.0003)$ & $(0.0004)$ & $(0.0004)$ \\
\hline \multirow[t]{2}{*}{ Set-aside subsidy } & $0.0020^{* * *}$ & $-0.0008^{*}$ & $-0.0010^{*}$ \\
\hline & $(0.0004)$ & $(0.0005)$ & $(0.0004)$ \\
\hline \multirow[t]{2}{*}{ Fertilizer price } & $0.0282^{* * *}$ & $-0.0938^{* * *}$ & $-0.1393^{* * *}$ \\
\hline & $(0.0086)$ & $(0.0112)$ & $(0.0096)$ \\
\hline \multirow[t]{2}{*}{ Pesticide price } & $0.0204^{* *}$ & $0.0758^{* * *}$ & $-0.0270^{* * *}$ \\
\hline & $(0.0095)$ & $(0.0127)$ & $(0.0104)$ \\
\hline
\end{tabular}

${ }^{*} \mathrm{p}<0.1 ;{ }^{* *} \mathrm{p}<0.05 ;{ }^{* * *} \mathrm{p}<0.01$

Standard errors in parentheses 
Table 4: Elasticities of land allocation calculated at the sample mean

\begin{tabular}{|c|c|c|c|c|}
\hline with respect to & Wheat area & Barley area & Rapeseed area & Set-aside area \\
\hline \multirow[t]{2}{*}{ Wheat price } & $0.0196 * * *$ & $-0.0564^{* * *}$ & $0.0119^{* *}$ & $0.1655^{* * *}$ \\
\hline & $(0.0060)$ & $(0.0071)$ & $(0.0059)$ & $(0.0313)$ \\
\hline \multirow[t]{2}{*}{ Barley price } & $-0.0369 * * *$ & $0.0653^{* * *}$ & $-0.0168^{* * *}$ & $-0.0358^{*}$ \\
\hline & $(0.0035)$ & $(0.0052)$ & $(0.0041)$ & $(0.0211)$ \\
\hline \multirow[t]{2}{*}{ Rapeseed price } & -0.0027 & $-0.0319^{* * *}$ & $0.0488^{* * *}$ & $-0.0423^{* *}$ \\
\hline & $(0.0027)$ & $(0.0036)$ & $(0.0037)$ & $(0.0172)$ \\
\hline \multirow[t]{2}{*}{ Wheat subsidy } & 0.0022 & $-0.0166^{* *}$ & $0.0407^{* * *}$ & $-0.1551^{* * *}$ \\
\hline & $(0.0018)$ & $(0.0068)$ & $(0.0077)$ & $(0.0410)$ \\
\hline \multirow[t]{2}{*}{ Barley subsidy } & $-0.0130^{* *}$ & $0.0735^{* * *}$ & $-0.0516^{* * *}$ & $-0.1436^{* * *}$ \\
\hline & $(0.0053)$ & $(0.0125)$ & $(0.0091)$ & $(0.0450)$ \\
\hline \multirow[t]{2}{*}{ Rapeseed subsidy } & $0.0252^{* * *}$ & $-0.0409 * * *$ & 0.0119 & 0.0146 \\
\hline & $(0.0048)$ & $(0.0072)$ & $(0.0105)$ & $(0.0458)$ \\
\hline \multirow[t]{2}{*}{ Set-aside subsidy } & $-0.0231^{* * *}$ & $-0.0273^{* * *}$ & 0.0035 & $0.4361^{* * *}$ \\
\hline & $(0.0061)$ & $(0.0086)$ & $(0.0110)$ & $(0.0818)$ \\
\hline \multirow[t]{2}{*}{ Fertilizer price } & $0.0116^{* * *}$ & $-0.0097^{* * *}$ & -0.0028 & -0.0200 \\
\hline & $(0.0022)$ & $(0.0029)$ & $(0.0030)$ & $(0.0168)$ \\
\hline \multirow[t]{2}{*}{ Pesticide price } & $-0.0081^{* *}$ & 0.0068 & -0.0013 & 0.0342 \\
\hline & $(0.0039)$ & $(0.0049)$ & $(0.0069)$ & $(0.0418)$ \\
\hline
\end{tabular}

${ }^{*} \mathrm{p}<0.1 ;{ }^{* *} \mathrm{p}<0.05 ;{ }^{* * *} \mathrm{p}<0.01$

Standard errors in parentheses 


\subsubsection{Elasticity estimates}

The results presented in Table 2 show that farmers tend to demand more fertilizers and pesticides in a context of high rapeseed prices. Our empirical estimates of the elasticities of demand for fertilizers and pesticides with respect to rapeseed price are both positive and statistically significant at the $1 \%$ level: 0.1789 for fertilizer demand and 0.0370 for pesticide demand. For other crops, we obtain the following results. The barley price has a positive and significant effect on fertilizer demand but a negative and significant effect on pesticide demand. In the case of wheat, the crop price negatively and significantly affects demand for both fertilizers and pesticides.

Our estimates of chemical input demand with respect to rapeseed price are positive for both fertilizer and pesticide. Moreover, it appears that demand for fertilizers is more responsive than demand for pesticides to the rapeseed price. Moro and Sckokai (1999) find that elasticity estimates with respect to crop prices are negative for maize, other cereals, and oilseeds, but positive for other field crops (0.063). Williams and Shumway (2000) estimate that for the US elasticity of pesticides with respect to food grain prices is negative $(-0.427)$, but positive for other field crops (0.461). For fertilizers, U.S. elasticity estimates with respect to crop prices are negative for both food grains and other field crops $(-0.090$ and -0.023 respectively).

Let us look now at the link between demand for chemicals and area-subsidy rates. In the case of fertilizers, subsidies for barley area, rapeseed area and set-aside land positively affect fertilizer demand, but only the effect of the barley-area subsidy is significant. The wheat area subsidy has a negative and significant effect on fertilizer demand. In the case of pesticides, area-payments for rapeseed and wheat have a positive effect on pesticide demand, but the effect is not significant for rapeseed subsidy. Barley area and set-aside land subsidies negatively affect pesticide demand but their effect is not significant. Laukkanen and Nauges (2014) estimate that area-based subsidies for grains increase total fertilizer and pesticide use, while set-aside subsidies decrease it.

Our estimation results show first that the effects of area-payments on the demand for chemicals differ significantly among crops - in our case rapeseed, barley, and wheat. More importantly, our results show that in all cases where the coefficients are significant, the demand for chemicals is more responsive to crop prices than to subsidy rates. For example, in the case of fertilizers, demand is more elastic (in absolute value) with respect to the wheat price than to the wheat area subsidy. This finding also holds for the barley price and barley area subsidy. In the case of pesticides, demand is more elastic with respect to wheat price than to wheat area subsidy.

We now present, in Table 4, the results related to elasticities involving land allocation decisions with respect to crop prices and subsidy rates. First, they are responsive to the price of 
their respective crops. Second, they are positively influenced by their respective subsidies.

Let us now summarize our findings. We note that higher rapeseed prices increase demand for both fertilizers and pesticides. Furthermore, increased rapeseed prices induce farmers to expand their land area allocated to rapeseed at the expense of barley and set-aside land. These findings confirm the argument in Nelson and Robertson (2008) that higher prices for biofuel crops encourage farmers to intensify cultivation of these crops and also to convert some land area to biofuel crops.

\subsubsection{Own-price and cross-price effects}

As shown in Tables 3,4, with the exception of wheat output and rapeseed area, all own-price elasticities of output and own-subsidy elasticities of land are significantly different from 0. Supply of barley and rapeseed is inelastic with respect to their own-prices. Note also that the supply of wheat, barley, and rapeseed is inelastic with respect to their area-subsidies. Nonetheless, the positive but inelastic elasticities with respect to subsidies confirm that CAP aid in the period 2006-2009 is not fully decoupled.

All cross-price elasticities of output are negative. Also most of the significant cross-subsidy elasticities of land are negative (with the exception of that between wheat and rapeseed, which is significantly positive).

Table 2 shows that the own-price elasticity of fertilizer demand is significantly different from 0 ; this is not the case for pesticide demand. Fertilizer demand has a significant own-price elasticity of -0.28 . Estimates of own-price elasticity of fertilizers and pesticides are infrequent in the literature; these two inputs are usually aggregated due to data limitations. Our estimate of the own-price elasticity of fertilizers is slightly lower than those estimated by Lacroix and Thomas 2011): -0.371 (t-statistic: -1.97 ) for France, and Williams and Shumway (2000) for the US -0.44 (standard error: 0.095) and Mexico -0.46 (standard error: 0.0874).

There are a few estimates of the own-price elasticity of pesticides for the US or the Netherlands $9^{9}$ Our results indicate an estimated own-price elasticity of pesticides of -0.026 but it is not significant. In our estimations, the non-significance of pesticide elasticity with respect to its own-price could be explained by lower time-series variation in pesticide expenditure than in fertilizer expenditure. Our estimate is lower in absolute value than the estimates in the literature, which range from -1.2 to -0.1 . For instance, Williams and Shumway (2000) provide a larger absolute value of the own-price elasticity of pesticides, namely -0.25 (standard error: 0.053 ) for the US and -0.28 (standard error: 0.1755 ) for Mexico. For pesticides, it is well known that

\footnotetext{
${ }^{9}$ See, for instance, INRA-CEMAGREF $[2005)$ (chapter 5, p.75) for a list of estimates found in the literature.
} 
the technical dependence of conventional production systems vis-à-vis the use of pesticides is reflected economically by a low elasticity of demand for pesticides relative to their price (INRACEMAGREF (2005), p.25). Carpentier (2010) also notes that these elasticities are usually small in absolute value in the long run and very small in the short run.

In our study, the cross-price elasticity of fertilizer demand with respect to pesticide price is negative and significantly different from zero. This finding indicates that these two inputs are complements in agricultural production.

\subsection{Simulations and discussion}

Given the extent of nitrogen and pesticide pollution in French water bodies, it is interesting to simulate the impact on demand for agro-chemicals of high rapeseed prices driven by biofuel policies. To conduct this simulation exercise, we use three different assessments from the literature on the evolution of oilseed prices, partly driven by EU biofuel policies. Louhichi and Valin (2012) estimate an increase of $43 \%$ in the price for rapeseed in the EU by 2020 under the scenario of the current EU biofuel mandate as defined by the 2009 Renewable Energy Directive. This scenario assumes an incorporation rate of $7.7 \%$ for first generation biofuels in the total fuel used in the transport sector. We also use two other assessments of the increase in oilseed prices at the international level related to EU biofuel policies: $32 \%$ (Britz and Leip, 2008), and 9\% AGRI (2007).

We use these assessments to simulate the impacts of such price variations on demand for agro-chemicals in France. To do this, we take into account our elasticity estimates of chemicals demand with respect to the rapeseed price. We are aware that our estimates are based on a specific sample from one département out of a total of 96 in Metropolitan France over a specific time period (2006-2009). However, as subsection 4.1 shows, our data set is representative of the whole département in terms of acreage, and of a large number of regions in France in terms of chemicals usage levels. The outcomes of this simulation exercise are summarized in Table 5

It emerges that demand for fertilizers will increase by $+1.6 \%$ to $+7.69 \%$ by 2020 due to the rise in rapeseed prices driven by EU biofuel policies. The increase will be lower for pesticide demand: from $+0.33 \%$ to $+1.6 \%$.

In the last column of Table 5, we report the simulated tax on fertilizers needed to overcome the implied increase in fertilizer demand due to higher rapeseed prices partly driven by EU biofuel policies ${ }^{10}$ Using our estimate of the own-price elasticity of fertilizers $(-0.28)$, and depending on the various price scenarios, the corresponding fertilizer price variation ranges between $+5.71 \%$

\footnotetext{
${ }^{10}$ Note that there is no room here for a tax to reduce pesticide demand because its own-price elasticity is not
} significant. 
Table 5: Variation in agro-chemicals demand and the fertilizer taxes required according to different oilseed prices

\begin{tabular}{lcccc}
\hline & $\begin{array}{c}\text { Oilseed price } \\
(\%)\end{array}$ & $\begin{array}{c}\text { Fertilizer demand } \\
(\%)\end{array}$ & $\begin{array}{c}\text { Pesticide demand } \\
(\%)\end{array}$ & $\begin{array}{c}\text { Tax on fertilizers } \\
(€ / \mathrm{kg})\end{array}$ \\
\hline Louichi and Vallin (2012) & $43 \%$ & $7.69 \%$ & $1.6 \%$ & 0.27 \\
Britz and Leip (2008) & $32 \%$ & $5.72 \%$ & $1.19 \%$ & 0.20 \\
DG Agri (2007) & $9 \%$ & $1.60 \%$ & $0.33 \%$ & 0.05 \\
\hline
\end{tabular}

and $+27.46 \%$. Since the average price of fertilizers during the period under study (2006-2009) is $€ 0.98$ per $\mathrm{kg}$ (Eurostat), this corresponds to a fertilizer tax ranging between $€ 0.05$ per $\mathrm{kg}$ and $€ 0.27$ per $\mathrm{kg}$. These tax rates are of the same magnitude as those applied in some European countries. For instance, Sweden applies a tax on nitrogen fertilizers of $€ 0.19$ per $\mathrm{kg}$ (Mattheiss et al. 2013).

\section{Conclusion}

World crop prices increased dramatically during the period 2006-2009. In a context of high crop prices, farmers may tend to increase the amount of agro-chemical inputs they use both to increase yield and to manage risks related to crop production. These practices could, however, have potentially adverse environmental effects in terms of loss of biodiversity and increased water and air pollution. We estimated a structural econometric model to measure the effects of crop prices on demand for agro-chemical inputs and land allocation. The model tested the hypothesis that a rise in the rapeseed price increases demand for chemical inputs (fertilizers and pesticides), rapeseed being the principal feedstock for production of biodiesel in France. We studied individual farms observed in the period 2006 to 2009 in the French Département de la Meuse.

Our estimations of a multi-output profit function with farm-level panel data reveal that higher rapeseed prices increase demand for both fertilizers and pesticides. Furthermore, higher rapeseed prices encourage farmers to expand the area allocated to rapeseed at the expense of barley and set-aside. These results suggest that biofuel policies, through an increase in rapeseed prices, induce changes in chemicals demand and land allocation. These changes, in turn, may have potentially adverse effects on the environment, such as nitrogen runoff and water pollution. In the context of a link between chemicals demand and area-subsidy rates, our estimation 
results show, first, that the effects of subsidy rates on chemicals demand differ significantly from one crop to another - in our case rapeseed, barley, and wheat. Second, and more importantly, we find that in all cases where the coefficients are significant, demand for chemicals is more responsive to crop prices than to subsidy rates.

We discussed a policy option to limit the use of fertilizers. A fertilizer tax could be considered, given the significant negative own-price elasticity of fertilizer demand. Our simulation exercise suggests that a fertilizer tax ranging from $€ 0.05$ per $\mathrm{kg}$ to $€ 0.27$ per $\mathrm{kg}$ would be appropriate in response to the increase in fertilizer demand due to a higher rapeseed price, driven by EU biofuel policies. In France, a new fertilizer measure was announced by the French President during the 2nd French Environmental Conference in October 2013, to the effect that value-added tax on fertilizers would be increased; however, no details were supplied. This announcement has disappointed a number of environmental non-governmental organizations which were hoping for an environmental tax on fertilizers.

It is important to note that our modelling approach does not consider either uncertainty or production risk. Indeed, part of the variation in demand for agro-chemicals might be driven by uncertainty and production risk if farmers are not risk neutral. If this is the case, then the impact of crop prices on fertilizer and pesticide use as measured in the paper may be overestimated. The inclusion of uncertainty in the model could be the subject of a future study.

\section{References}

Abbott, P. C., Hurt, C. and Tyner, W. E. (2009). What's driving food prices? March 2009 Update. Tech. rep., Farm Foundation.

AGRI, D. (2007). The impact of a minimum $10 \%$ obligation for biofuel use in the EU-27 in 2020 on agricultural markets. Directorate G. Economic analysis, perspectives and evaluations. Internal Memo .

Arnade, C. and Kelch, D. (2007). Estimation of area elasticities from a standard profit function. American Journal of Agricultural Economics 89: 727-737.

Baier, S. L., Clements, M., Griffiths, C. W. and Ihrig, J. E. (2009). Biofuels impact on crop and food prices: using an interactive spreadsheet. FRB International Finance Discussion Paper.

Baltagi, B. H. (1995). Econometric Analysis of Panel Data. New York: John Wiley.

Boussemart, J.-P., Leleu, H. and Ojo, O. (2011). Could society's willingness to reduce pesticide use be aligned with farmers' economic self-interest? Ecological Economics 70: 1797 - 1804. 
Britz, W. and Leip, A. (2008). Analyzing economic and environmental impacts of first generation bio-fuel processing in the EU with the CAPRI-DNDC modelling chain. Presentation prepared for OECD Workshop 20 June 2008.

Butault, J.-P. (2004). Les soutiens à l'agriculture. Théorie, histoire, mesure. Inra Editions.

Carpentier, A. (2010). Economie de la production agricole et régulation de l'utilisation des pesticides, une synthèse critique de la littérature. Working Paper SMART-LERECO, INRA .

Chakir, R. and Hardelin, J. (2014). Hail insurance and pesticide use in french agriculture: an empirical analysis of multiple risks management. Review of Agricultural and Environmental Studies 95: 25-50.

Chambers, R. G. and Just, R. E. (1989). Estimating multioutput technologies. American Journal of Agricultural Economics 71: 980-995.

Delame, N. (2014). Estimation des usages d'azote minéral dans les exploitations agricoles. Working Paper UMR Economie Publique, INRA-AgroParisTech .

Fezzi, C. and Bateman, I. (2011). Structural agricultural land use modeling for spatial agroenvironmental policy analysis. American Journal of Agricultural Economics 93: 1168-1188.

Greene, W. H. (2008). Econometric analysis. Pearson Education India, 6th ed.

Hausman, C. (2012). Biofuels and land use change: Sugarcane and soybean acreage response in brazil. Environmental \&6 Resource Economics 51(2): 163-187.

INRA-CEMAGREF (2005). Pesticides, agriculture et environnement: Réduire l'utilisation des pesticides et en limiter les impacts environnementaux. Tech. rep., Expertise Scientifique Collective, Rapport final.

Katell, P. and Michon, J. (2015). The status of surface water and groundwater. Tech. rep., Les synthèses Eaufrance - n 12. Office national de l'eau et des milieux aquatiques (Onema).

Lacroix, A. and Thomas, A. (2011). Estimating the environmental impact of land and production decisions with multivariate selection rules and panel data. American Journal of Agricultural Economics 93(3): 784-802.

Langpap, C. and Wu, J. (2011). Potential environmental impacts of increased reliance on cornbased bioenergy. Environmental and Resource Economics 49: 147-171.

Lankoski, J. and Ollikainen, M. (2011). Biofuel policies and the environment: Do climate benefits warrant increased production from biofuel feedstocks? Ecological Economics 70: 676-687. 
Laukkanen, M. and Nauges, C. (2014). Evaluating greening farm policies: a structural model for assessing agri-environmental subsidies. Land Econmics 90(3): 458-481.

Louhichi, K. and Valin, H. (2012). Impact of EU biofuel policies on the french arable sector: A micro-level analysis using global market and farm-based supply models. Review of Agricultural and Environmental Studies 93: 233-272.

Mattheiss, V., Goral, F., Volz, P. and Strosser, P. (2013). Economic instruments for mobilizing financial resources for supporting IWRM. additional information and illustrations for the OECD initiative. ACTeon's support to the OECD initiative on financing IWRM.

Moro, D. and Sckokai, P. (1999). Modelling the CAP arable crop regime in Italy: Degree of decoupling and impact of Agenda 2000. Cahiers d'Economie et Sociologie Rurales 0: 49-73.

Nelson, G. C. and Robertson, R. D. (2008). Green gold or green wash: environmental consequences of biofuels in the developing world. Applied Economic Perspectives and Policy 30: $517-529$.

Platoni, S., Sckokai, P. and Moro, D. (2012). Panel data estimation techniques and farm-level data models. American Journal of Agricultural Economics 94(5): 1202-1217.

Searchinger, T., Heimlich, R., Houghton, R. A., Dong, F., Elobeid, A., Fabiosa, J., Tokgoz, S., Hayes, D. and Yu, T.-H. (2008). Use of US croplands for biofuels increases greenhouse gases through emissions from land-use change. Science 319: 1238-1240.

Secchi, S., Babcock, B. A. et al. (2007). Impact of high crop prices on environmental quality: A case of Iowa and the conservation reserve program. Working Paper.

Secchi, S., Jha, P. W. G. M., Kurkalova, L. and Kling, C. L. (2011). Potential water quality changes due to corn expansion in the upper Mississippi river basin. Ecological Applications 21(4): 1068-1084

Timilsina, G. and Mevel, S. (2013). Biofuels and climate change mitigation: A CGE analysis incorporating land-use change. Environmental and Resource Economics 55(1): 1-19.

Williams, S. P. and Shumway, C. R. (2000). Trade liberalization and agricultural chemical use: United States and Mexico. American Journal of Agricultural Economics 82: 183-199. 